\title{
Carbohydrate utilization in the pre-ruminant calf
}

\author{
By R. C. SIDDONS, R. H. SMITH, M. J. HENSCHEL, \\ W. B. HILL AND J. W. G. PORTER \\ National Institute for Research in Dairying, Shinfield, Reading
}

(Received 2 October 1968-Accepted 16 Fanuary 1969)

\begin{abstract}
1. Changes in blood sugar levels after giving carbohydrates have been used to assess carbohydrate utilization in pre-ruminant calves aged between ro and 50 days.

2. Glucose, galactose and lactose were readily utilized by all calves; the utilization of glucose and galactose increased with age, whereas that of lactose remained constant.

3. Maltose and fructose utilization was low in young calves and increased slightly with age.

4. Sucrose and starch were not utilized.

5. Studies with three older pre-ruminant calves (aged 53, 88 and 106 days) in which the carbohydrates were infused into the proximal duodenum showed that glucose, galactose, lactose and xylose all caused marked increases in the level of blood reducing sugar, whereas fructose and sucrose caused no increase, and maltose was intermediate. Xylose and galactose caused very little change in the blood glucose concentration.

6. It appeared that preferential uptake occurred of glucose from a glucose-galactose mixture.

7. A non-linear relationship was found between the concentration of glucose or galactose infused and the increase in the level of blood reducing sugar.
\end{abstract}

Since it is essential that the carbohydrate content of milk replacer diets for young calves be in a readily available form, a knowledge of the ability of the calf to utilize carbohydrates is of fundamental importance in the development of such diets.

It is well established that the young pre-ruminant calf readily utilizes glucose, galactose and lactose, but not sucrose, maltose and starch (Dollar \& Porter, 1957,1959; Flipse, Huffman, Duncan \& Webster, 1950; Okamoto, Thomas \& Johnson, 1959). Most of the studies with older calves have been with ruminating animals, and have shown that glucose and lactose are well utilized, although the ability to utilize lactose decreases with age (Huber, Jacobson, McGilliard \& Allen, 196r). Maltose is also utilized to some extent (Larsen, Stoddard, Jacobson \& Allen, I956). The extent to which sucrose and starch are available to older calves is less clear since the apparent utilization of these sugars in digestion trials (Huber, Jacobson, McGilliard, Morrill \& Allen, 1961) is not substantiated by blood sugar studies (Huber, Jacobsen, McGilliard \& Allen 196r; Larsen et al. 1956; Larsen \& Stoddard, 1953).

In the published studies of carbohydrate utilization in the calf very little emphasis has been placed on the effect of age. Therefore, in the present work we have measured the changes in the concentration of blood sugar after giving pre-ruminant calves, aged between 10 and 50 days various carbohydrates by mouth, and after infusing carbohydrates into the small intestine of older pre-ruminant calves. For the purposes of discussion we have considered these changes to be a measure of carbohydrate utilization, although we realize that the absorption and appearance of a sugar in the blood do not necessarily imply that the sugar is subsequently metabolized. Thus, when 
monosaccharides are being considered, the word 'utilization' is naturally synonymous with 'absorption', whereas in the case of disaccharides and polysaccharides it implies 'digestion and absorption'.

\section{EXPERIMENTAL}

Animals. A total of twenty-one Ayrshire, Shorthorn and Friesian bull calves was used in experiments in which carbohydrates were given by mouth. In experiments in which carbohydrates were infused into the duodenum, three bull calves, a Guernsey, a Hereford-Friesian crossbred and a Friesian, were used. Intestinal fistulas were inserted into the proximal duodenum when the calves were 19,33 and 48 days old, respectively, and infusion experiments were started at 53, Io6 and 88 days of age.

All newborn calves were reared for 2 days on colostrum and thereafter on a wholemilk diet fed at a rate sufficient to realize an increase in body-weight of approximately $0.25 \mathrm{~kg} /$ day (Roy, Shillam, Hawkin \& Lang, 1958). The calves were muzzled to prevent access to roughage.

Feeding experiments. After overnight fasting the animals were given either water, or solutions of glucose, galactose, fructose, lactose, maltose, sucrose or soluble starch in $2 \cdot 25$ l. of water at the rate of $4 \cdot 4 \mathrm{~g}$ carbohydrate $/ \mathrm{kg}$ body-weight. Samples of jugular blood were taken through a polyethylene cannula which was inserted into the jugular vein at least $30 \mathrm{~min}$ before feeding. Duplicate $0.2 \mathrm{ml}$ samples were taken immediately before feeding and $0.5, \mathrm{I}, \mathrm{x} \cdot 5,2,3,4,5$ and $6 \mathrm{~h}$ after feeding and the cannula was then removed. In some experiments samples of portal blood were also obtained from a permanent cannula into the portal vein.

Infusion of carbohydrates into the duodenum. The calves were starved overnight and then given a feed of calcium caseinate ( $100-\mathrm{r} 25 \mathrm{~g}$ ) dispensed in $2.95 \mathrm{l}$. of a solution of minerals of a composition similar to those in milk. It was shown in preliminary experiments with calves with re-entry duodenal fistulas that with this feed there was a fairly constant rate of flow of digesta from the abomasum of about $400-500 \mathrm{ml} / \mathrm{h}$ between $\mathrm{I}$ and $4 \mathrm{~h}$ after the meal. A single calf was used in a series of twenty-seven experiments in which $14 \%(\mathrm{w} / \mathrm{v})$ solutions of various sugars in $0.9 \%(\mathrm{w} / \mathrm{v}) \mathrm{NaCl}$ were infused into a fistula in the most proximal duodenum at a rate of about $3 \mathrm{ml} / \mathrm{h}$ per $\mathrm{kg}$ bodyweight. Two further calves were used in a series of eighteen experiments in which separate or combined solutions of glucose and galactose at concentrations ranging from 5 to $50 \%(\mathrm{w} / \mathrm{v})$ were similarly infused. Infusion began $\mathrm{xh}$ after feeding and continued for $4 \mathrm{~h}$. Blood samples were taken from the jugular vein immediately before the infusion commenced and at intervals thereafter, the last sample being taken $2 \mathrm{~h}$ after the infusion stopped.

Blood sugar determinations. The $0.2 \mathrm{ml}$ blood samples were pipetted into $3.0 \mathrm{ml}$ distilled water and deproteinized by the addition of $0.4 \mathrm{ml}$ each of $5 \%(\mathrm{w} / \mathrm{v})$ zinc sulphate and $0.3 \mathrm{~N}$-barium hydroxide solutions. The total reducing sugar content of the supernatant fraction was determined with Somogyi's (copper) reagent (Somogyi, I952) and Nelson's (arsenomolybdate) chromogenic reagent (Nelson, I944). The glucose content of the supernatant fraction was determined with a tris-glucose oxidase reagent (Dahlquist, I960). 
RESULTS

\section{Effect of age on the change in the blood sugar levels after feeding different carbohydrates}

Studies were performed on calves of mean age Io days (range 6- $x_{4}$ days), 30 days (range $25-35$ days) and 50 days (range 44-56 days). The mean blood sugar level of fasted calves was found to decrease with age (Table r).

Table I. Mean values with their standard errors for the blood sugar concentrations of calves after overnight fasting

$\begin{array}{ccccc}\begin{array}{c}\text { Age group } \\ \text { (days) }\end{array} & \begin{array}{c}\text { Age range } \\ \text { (days) }\end{array} & \begin{array}{c}\text { No. of calves } \\ \text { in group }\end{array} & \begin{array}{c}\text { Reducing sugar } \\ (\mathrm{mg} / \mathrm{l} 00 \mathrm{ml})\end{array} & \begin{array}{c}\text { Glucose } \\ (\mathrm{mg} / \mathrm{l} 00 \mathrm{ml})\end{array} \\ \text { 10 } & 6-14 & 16 & 106 \cdot 9 \pm 6 \cdot 8 & 102 \cdot 8 \pm 7 \cdot 1 \\ 30 & 25-35 & 1 \mathrm{I} & 81 \cdot 5 \pm 6 \cdot 2 & 77 \cdot 4 \pm 4 \cdot 0 \\ 50 & 44-56 & 19 & 71 \cdot 3 \pm 3 \cdot 5 & 70 \cdot \mathrm{I} \pm 3 \cdot 3\end{array}$
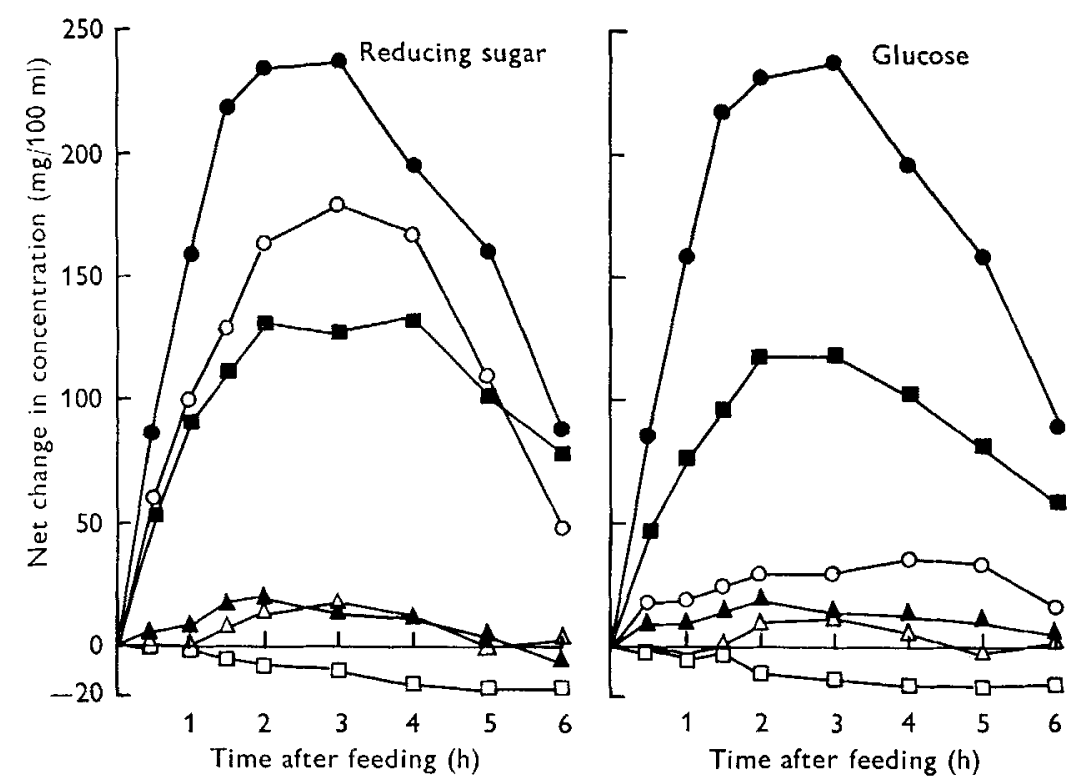

Fig. 1. Change with time in the reducing sugar and glucose concentrations in the blood of 50-day-old calves after the ingestion of water or solutions of various carbohydrates. glucose; $O-O$, galactose; $\mathbf{\square - \boldsymbol { n }}$, lactose; $\boldsymbol{\Delta}-\boldsymbol{\Delta}$, maltose; $\triangle-\triangle$, fructose; $\square-[]$, water.

After feeding a utilizable carbohydrate there was an increase in the blood sugar concentration (Fig. I). The increase was greatest in the first $2 \mathrm{~h}$, usually reached a maximum between 2 and $3 \mathrm{~h}$ and decreased subsequently. The curves shown in Fig. I are typical of the responses obtained with calves in all age groups, though it was found that the magnitude of the response varied with age and with the particular sugar ingested (Fig. 2).

Glucose caused a marked increase in the concentrations of blood reducing sugar and blood glucose in calves in all age groups. However, the rate of increase and the 
maximum concentration attained were greater in the 50-day-old group than in the

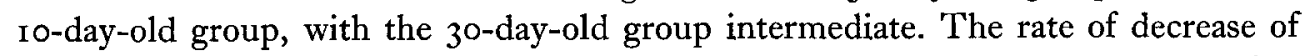
the blood sugar concentration was also more rapid in the older calves, and $6 \mathrm{~h}$ after glucose had been given the blood sugar concentration was similar in all three age groups. This $6 \mathrm{~h}$ concentration was greater than the fasting level by $50-80 \mathrm{mg} / \mathrm{r} 00 \mathrm{ml}$.

Galactose also caused a marked increase in the concentration of blood reducing sugar when fed to fasted calves, and, as with glucose, the response was greatest in the oldest calves. In the ro- and 30 -day-old groups the increase in the concentration of blood reducing sugar after feeding with galactose was very similar to the increase observed after feeding with glucose. In the 50-day-old group, however, the response with galactose was lower than with glucose, the maximum increases being $\mathrm{I} 8 \mathrm{I}$ and $238 \mathrm{mg} / \mathrm{roo} \mathrm{ml}$, respectively. The rise in the blood glucose level after feeding with galactose was small in all age groups.
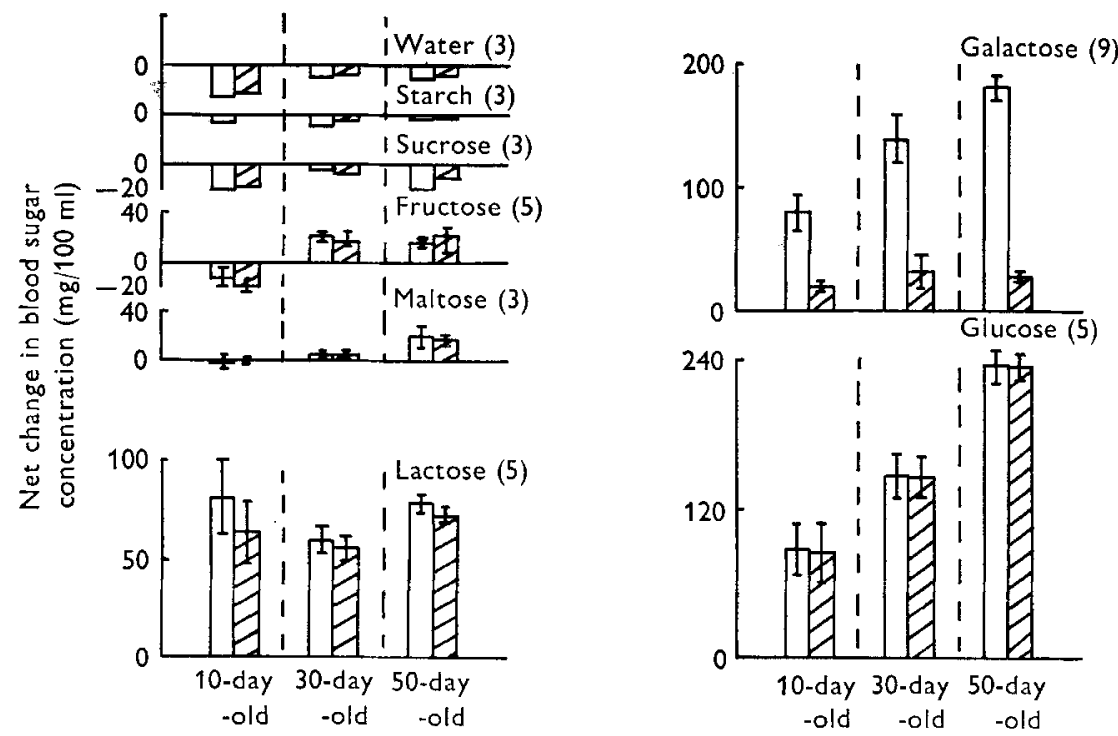

Fig. 2. The net change in the reducing sugar $(\square)$ and glucose $(\mathbb{Z})$ concentration in the blood of calves of different ages after the ingestion of various carbohydrates. The result for an individual experiment was calculated as the difference between a sample taken before feeding and a mean value for samples taken 2 and $3 \mathrm{~h}$ after feeding. The over-all mean values presented were obtained from calves of mean age 10,30 and 50 days. The figures in parentheses are the number of experiments performed in each age group and the standard errors of the means are indicated by vertical bars.

Lactose caused marked increases in the levels of both the blood reducing sugar and blood glucose when fed to fasted calves, but with little difference between the different age groups. Almost all the increase in blood sugar after a dose of lactose was due to glucose. In the ro-day-old group the response to lactose was in fact greater than the response to glucose or galactose, whereas in the 30 - and 50 -day-old groups the reverse was true.

The ingestion of maltose resulted in only small increases in the blood sugar level of all calves; the response was lowest in the youngest calves and increased slightly with 
age. The response to fructose was also increased with age: with the Io-day-old group there was no increase in the blood sugar level, whereas there were small increases with the 30- and 50-day-old groups. Neither sucrose nor starch caused an increase in the blood sugar concentration.

The concentrations of reducing sugar and glucose in portal and jugular blood were very similar both before and after the ingestion of either glucose or lactose. In fifteen samples taken the glucose and reducing sugar concentrations $( \pm \mathrm{SD})$ in jugular blood were respectively $95 \cdot \mathrm{I} \pm 3 \cdot 9 \%$ and $96 \cdot 5 \pm 2 \cdot \mathrm{r} \%$ of the portal concentrations.

\section{Infusion studies}

Examples are shown in Fig. 3 of the changes found in the levels of reducing sugar in blood during infusion experiments. The rate of change of blood sugar concentration was always approximately linear during the first $2.25 \mathrm{~h}$ of the infusion. Consequently the net changes during the first $2 \mathrm{~h}$ were used to compare the utilization of different carbohydrates. The results in Table 2 show that glucose, galactose, lactose and xylose caused marked increases in the level of blood reducing sugar, whereas maltose caused only a small increase and sucrose and fructose were without effect. With glucose and maltose the increase in the concentration of blood glucose was similar to the increase in the concentration of blood reducing sugar, whereas with galactose there was only a small increase in the blood glucose concentration and with xylose there was no increase.

\section{Table 2. Net changes in the blood sugar concentrations of calves after the infusion of various carbohydrates into the duodenum}

(The carbohydrates were infused as $14 \%(\mathrm{w} / \mathrm{v})$ solutions in $0.9 \%(\mathrm{w} / \mathrm{v})$ saline. The recorded values refer to the net change between $O$ and $2 h$ and are the mean of three results for each carbohydrate)

\begin{tabular}{|c|c|c|}
\hline \multirow[b]{2}{*}{ Carbohydrate infused } & \multicolumn{2}{|c|}{$\begin{array}{l}\text { Net change in concentration } \\
(\mathrm{mg} / 100 \mathrm{ml})\end{array}$} \\
\hline & Reducing sugar & Glucose \\
\hline Glucose & $48 \cdot 9$ & $49 \cdot 4$ \\
\hline Galactose & $40 \cdot 0$ & 12.5 \\
\hline Glucose + galactose & $47^{\circ} 7$ & $38 \cdot 6$ \\
\hline Lactose & $42 \cdot 4$ & $26 \cdot 3$ \\
\hline Maltose & $17 \% 4$ & $15 \cdot 3$ \\
\hline Xylose & $46 \cdot 4$ & -3.7 \\
\hline Fructose & -3.4 & -10.4 \\
\hline Sucrose & $-9 \cdot 3$ & $-5 \cdot 6$ \\
\hline None & $-2 \cdot 0$ & $-5 \cdot 2$ \\
\hline $\begin{array}{l}\text { Standard error of differ- } \\
\text { ence between } 2 \text { means } \\
\text { ( } 16 \mathrm{df} \text { ) }\end{array}$ & \pm 10.58 & $\pm 6 \cdot 70$ \\
\hline $\begin{array}{l}5 \% \text { least significant differ- } \\
\text { ence between } 2 \text { means }\end{array}$ & $\pm 22 \cdot 43$ & $\pm I 4 \cdot 2 I$ \\
\hline
\end{tabular}

When a mixture of $7 \%(\mathrm{w} / \mathrm{v})$ glucose and $7 \%(\mathrm{w} / \mathrm{v})$ galactose was infused (Table 2$)$ the increase in the blood glucose concentration was greater than that expected if the two sugars were absorbed independently from the mixture, thus suggesting a preferential uptake of glucose. This was even more apparent in experiments in which the 
concentration of carbohydrate in the infused solution was increased to $25 \%(\mathrm{w} / \mathrm{v})$ and $50 \%(\mathrm{w} / \mathrm{v})$ (Fig. 4). Glucose at these levels caused marked increases in the concentration of both the blood reducing sugar and blood glucose. Galactose also caused large increases in the concentration of blood reducing sugar, but only small increases in that of the blood glucose. The infusion of $25 \%(\mathrm{w} / \mathrm{v})$ glucose with $25 \%(\mathrm{w} / \mathrm{v})$ galactose resulted in an increase in the reducing sugar concentration of the blood only slightly greater than when the individual sugars were infused at the $25 \%(\mathrm{w} / \mathrm{v})$ level and this increase was almost entirely due to an increase in glucose.

In Fig. 5 the increase in the concentration of blood reducing sugar is plotted against

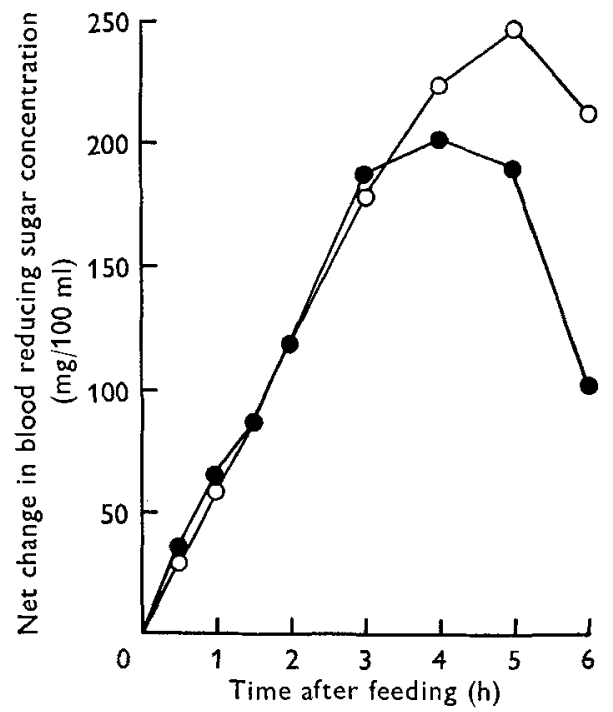

Fig. 3. Typical examples of the increases in the blood reducing sugar concentration of calves after the infusion of $50 \%(\mathrm{w} / \mathrm{v})$ glucose $(-)$ and $50 \%(\mathrm{w} / \mathrm{v})$ galactose $(\mathrm{O}-\mathrm{O})$ at $300 \mathrm{ml} / \mathrm{h}$ for $4 \mathrm{~h}$.
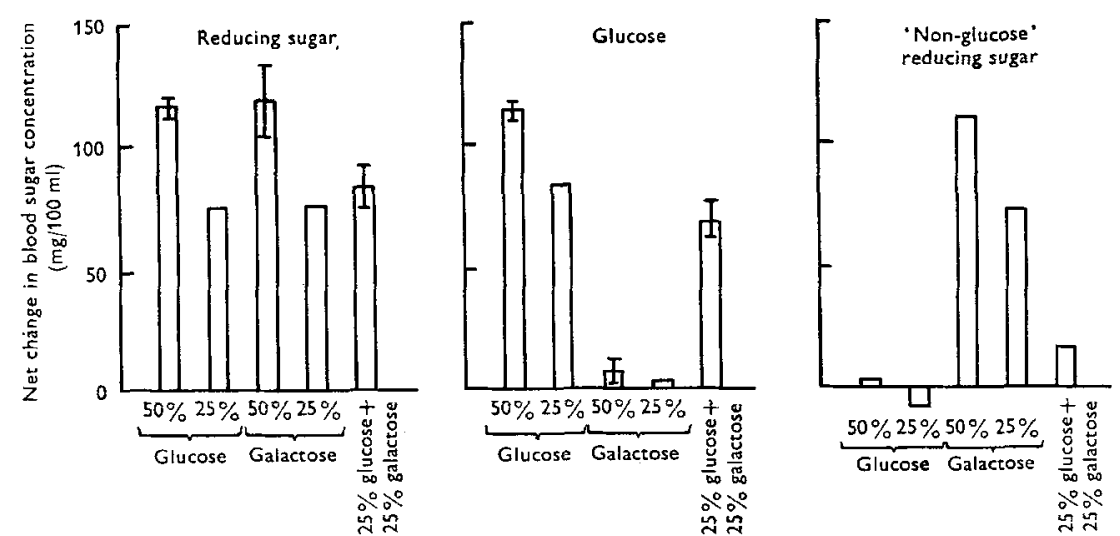

Fig. 4. The response in the blood sugar level of calves to the infusion $(300 \mathrm{ml} / \mathrm{h})$ of glucose, galactose and glucose + galactose. The results are recorded as the net changes in the first $2 \mathrm{~h}$ after the infusion started. Three separate experiments were performed with the $50 \%$ sugar concentration and the standard errors of the mean values are indicated by the vertical bars. The ' non-glucose' reducing sugar was obtained by subtracting the glucose concentration from the reducing sugar concentration. 
the concentration of glucose or galactose infused. It is evident from Fig. 5 that both sugars were equally well absorbed at rates which continued to increase as the concentration of carbohydrate was raised to $2 \mathrm{~g} / \mathrm{h}$ per $\mathrm{kg}$ body-weight. At higher concentrations the calves scoured, indicating that the absorptive capacity of the small intestine was saturated and that sugar was reaching the large intestine.

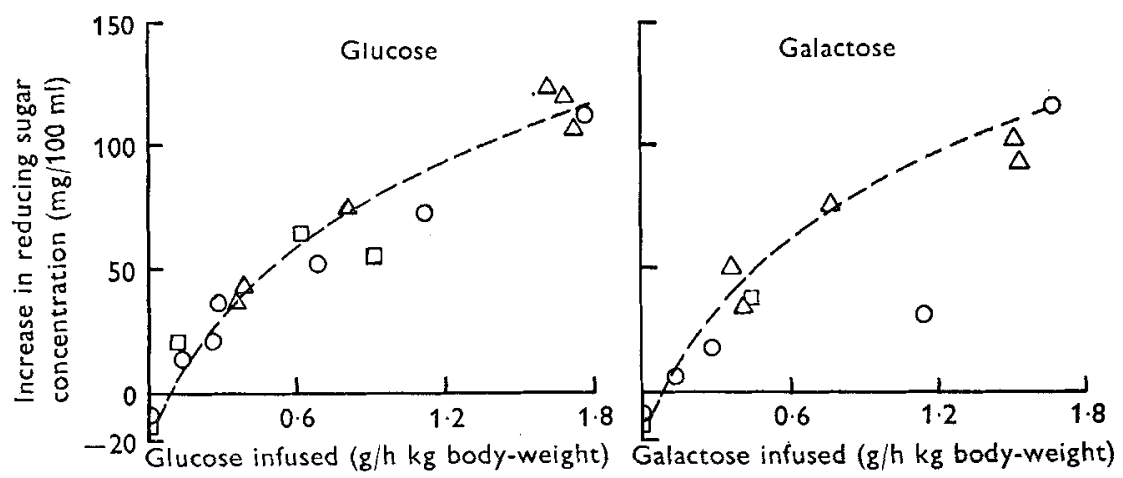

Fig. 5. The effect of the concentration of glucose or galactose infused on the increase in the blood reducing sugar concentration. The results are the net changes $2 \mathrm{~h}$ after the infusion started. The different symbols refer to the results with different calves.

\section{DISCUSSION}

It has been known for some time that the blood sugar level of the young calf is much greater than that of the adult bovine (Kennedy, Anderson, Bechdel \& Shigley, 1939). The decline in the blood sugar level occurs in the first weeks of life, and McCandless \& Dye (1950) have suggested that it results from the development of the rumen. This may only be partly true since our studies and the studies of other workers (Warner, Bernholdt, Grippin \& Loosli, 1953; Conrad, Hibbs \& Pounden, 1954) have shown a decline with age in the blood sugar level of calves in which rumen development was restricted by the feeding of whole-milk diets. However, the decrease in the blood sugar level of milk-fed calves was not as great as in calves receiving roughage.

Our results with pre-ruminant calves confirm the findings of similar studies previously reported by Dollar \& Porter (1959) and Okamoto et al. (1959). The young calf (mean age ro days) readily utilized glucose, galactose and lactose, possessed limited ability to utilize maltose and was unable to utilize fructose, sucrose or starch. With increasing age (up to $5^{\circ}$ days) an improvement was found in the calf's ability to utilize glucose and galactose, whereas the ability to utilize lactose remained relatively constant. Fructose and maltose utilization also improved slightly with age, but there was no evidence of sucrose or starch utilization in any of the calves used. These findings are also in general agreement with the results from similar studies with calves in which rumen development was allowed (Velu, Kendall \& Gardner, 1960). One notable difference, however, between our findings and those of Velu et al. (1960) was that with pre-ruminant calves we found a greater response to glucose ingestion in the $5^{\circ-}$ than in the 30-day-old group, whereas they found a markedly smaller response to glucose in 7 - than in 6-week-old calves.

Although there is some evidence that small quantities of disaccharides may be 
absorbed without hydrolysis (Chain, Mansford \& Pocchiari, 1960; Miller \& Crane, $\mathrm{I} 96 \mathrm{r} a, b)$, it is generally accepted that the utilization of dietary disaccharides or polysaccharides requires hydrolysis to monosaccharides before absorption can take place. The enzymes responsible for the hydrolysis are pancreatic amylase, which hydrolyses starch mainly to maltose, and the disaccharidases of the mucosal cells of the small intestine which hydrolyse disaccharides to monosaccharides. Experiments with rats (Koldovský, Muzycenková, Hahn, Hennojová \& Jirsová, I965) and rabbits (Sterk \& Kretchmer, 1964) have shown a correlation between the disaccharidase activity of the small intestine and disaccharide utilization. In the small intestine of the young calf lactase activity is high, maltase activity is low and sucrose activity is absent (Huber, Jacobson \& Allen, 196r; Siddons, 1968a, $b$ ). In older calves the lactase activity decreases although it is still relatively high in 4-month-old calves. The maltase activity does not change with age and sucrase activity could not be demonstrated even in the adult bovine. Such a developmental pattern for the intestinal disaccharidases of the calf correlates well with the present findings on the utilization of sugars as measured by the blood sugar response and indicates that the small intestinal disaccharidase activity of the calf is a controlling factor in disaccharide utilization. The inability of the calf to utilize starch may be partly a result of the limiting maltase activity in the small intestine although it is probable that the low level of pancreatic amylase activity is also a limiting factor (Keller, Cohen \& Neurath, 1958).

The absence of a marked increase in the blood sugar level of the calf after feeding or infusing fructose indicates that there is no utilization but does not prove that the sugar remains unchanged in the small intestine. Studies with the rat (Kiyasu \& Charkoff, 1957; Wilson, 1953; Wilson \& Wiseman, 1954) have shown that during the absorption of radioactive fructose (in the rat fructose is absorbed from the small intestine at a slower rate than glucose or galactose, but more rapidly than non-actively absorbed sugars) as much as $50 \%$ of the radioactivity appeared in the blood as lactic acid. The possibility that a similar mechanism may operate in the calf has not yet been investigated, though the severe scouring that occurs after feeding fructose indicates that much of the sugar passes unabsorbed through the intestine.

With the older calves it was possible to infuse sugars directly into the small intestine at constant known rates and thus obtain a more precise measure of the amount of sugar available for absorption. The results with the fistulated calves were generally similar to those with younger calves to which carbohydrates were fed. Glucose, galactose, lactose and xylose caused marked increases in the blood sugar level, maltose caused smaller increases and sucrose and fructose were without effect. When glucose and maltose were infused the increase in the blood reducing sugar levels was due entirely to an increase in the glucose content of the blood, whereas with xylose there was no increase in the blood glucose content and with galactose there was only a small increase. Thus the absorption of xylose and galactose from the small intestine is not accompanied by their conversion into glucose.

The results given in Fig. 4 show that blood glucose increased more rapidly than blood galactose when a solution containing equal amounts of each of these sugars was infused. This was consistent with galactose absorption being depressed by competition 
from glucose. Similar competition between actively absorbed sugars, and a preferential uptake of glucose from a glucose-galactose mixture, has been shown previously in the rat small intestine (Cajori, 1926; Fisher \& Parsons, 1953). Blood glucose also increased more rapidly than blood galactose after lactose was fed (Fig. 2).

Evidence for the active absorption of glucose and galactose from the calf small intestine can be derived from the finding of a non-linear relationship between the concentrations of glucose or galactose infused and the increase in the level of blood reducing sugar (Fig. 5). Sugars absorbed by passive diffusion would be expected to show a linear relationship between absorption and concentration, whereas actively absorbed sugars would be expected to exhibit saturation kinetics. The fact that neither of these situations held completely in our experiments with the calf is probably because diffusion occurred when the more concentrated solutions were infused. Forster \& Mehnert $(1965)$ observed a similar phenomenon when studying the in vivo absorption of sugars from the intestine of the rat.

We thank Dr A. T. Cowie and Mr S.C. Watson for carrying out all surgical operations and Miss S. J. Clacy and Mr R. J. Merry for technical assistance.

\section{REFERENCES}

Cajori, C. F. (1926). Proc. Soc. exp. Biol. Med, 23, 290.

Chain, E. B., Mansford, K. R. L. \& Pocchiari, F. (1960). F. Physiol., Lond. 154, 39.

Conrad, H. R., Hibbs, J. W. \& Pounden, W. D. (1954). F. Dairy Sci. 37, 664 -

Dahlqvist, A. (I960). Biochem. $尹$. 80, 547.

Dollar, A. M. \& Porter, J. W. G. (1957). Nature, Lond. 179, I 299.

Dollar, A. M. \& Porter, J. W. G. (1959). Proc. int. Dairy Congr. Xv. London. Vol. I, p. 185.

Fisher, R. B. \& Parsons, D. S. (1953). J. Physiol., Lond. 119, 224.

Flipse, R. J., Huffman, C. F., Duncan, C. W. \& Webster, H. D. (1950). F. Dairy Sci. 33, 557.

Forster, H. \& Mehnert, H. (1965). Klin. Wschr. 43, 834.

Huber, J. T., Jacobson, N. L. \& Allen, R. S. (1961). F. Dairy Sci. 44, 1494.

Huber, J. T., Jacobson, N. L., McGilliard, A. D. \& Allen, R. S. (I96I). F. Dairy Sci. 44, 321.

Huber, J. T., Jacobson, N. L., McGilliard, A. D., Morrill, J. L. \& Allen, R. S. (1961). F. Dairy Sci. 44, $\mathrm{I}_{4} 84$.

Keller, P. J., Cohen, E. \& Neurath, H. (1958). F. biol. Chem. 233, 344.

Kennedy, W. L., Anderson, A. K., Bechdel, S. I. \& Shigley, J. F. (I939). F. Dairy Sci. 22, 25 I.

Kiyasu, J. Y. \& Charkoff, I. L. (1957). F. biol. Chem. 224, 935.

Koldovský, O., Muzycenková, H., Hahn, P., Hennojová, A. \& Jirsová, V. (1965). Can. J. Physiol. Pharmacol. 43, 469 .

Larsen, H. J. \& Stoddard, G. E. (1953). F. Dairy Sci. 36, 601.

Larsen, H. J., Stoddard, G. E., Jacobson, N. L. \& Allen, R. S. (1956). J. Anim. Sci. 15, 473.

McCandless, E. L. \& Dye, J. A. (1950). Am. F. Physiol. r62, 434.

Miller, D. \& Cranc, R. K. (1961 a). Biochim. biophys. Acta 52, 281.

Miller, D. \& Crane, R. K. (1961 b). Biochim. biophys. Acta 52, 293.

Nelson, N. (1944). F. biol. Chem. 153, 375.

Okamoto, M., Thomas, J. W. \& Johnson, T. L. (1959). F. Dairy Sci. 42, 920.

Roy, J. H. B., Shillam, K. W. G., Hawkin, G. M. \& Lang, J. M. (1958). Br. J. Nutr. 12, I23.

Siddons, R. C. (1968a). Proc. Nutr. Soc. 27, r8A.

Siddons, R. C. (1 968 b). Biochem. F. I08, 839 .

Somogyi, M. (1952). F. biol. Chem. 195, 19.

Sterk, V. V. \& Kretchmer, N. (1964). Pediatrics, Springfield 34, 609.

Velu, J. G., Kendall, K. A. \& Gardner, K. E. (r960). F. Dairy Sci. 43, 546.

Warner, R. G., Bernholdt, H. F., Grippin, C. H. \& Loosli, J. K. (1953). F. Dairy Sci. 36, 599.

Wilson, T. H. (1953). Biochim. biophys. Acta II, 448 .

Wilson, T. H. \& Wiseman, G. (1954). F. Physiol., Lond. 123, I 16.

\section{Printed in Great Britain}

